\title{
Application of unstable Gfp variants to the kinetic study of Legionella pneumophila icm gene expression during infection
}

\author{
Correspondence \\ Oksana V. Barysheva \\ ksyusha@bact.med.kyushu-u.ac.jp
}

Received 10 September 2007

Revised 13 December 2007

Accepted 9 January 2008

\author{
Oksana V. Barysheva, ${ }^{1}$ Jun Fujii, ${ }^{1}$ Giichi Takaesu ${ }^{2}$ and Shin-ichi Yoshida ${ }^{1}$ \\ ${ }^{1}$ Department of Bacteriology, Faculty of Medical Sciences, Kyushu University, Fukuoka 812-8582, \\ Japan \\ ${ }^{2}$ Division of Molecular and Cellular Immunology, Medical Institute of Bioregulation, Kyushu \\ University, 3-1-1 Maidashi, Higashi-ku, Fukuoka 812-8582, Japan
}

An unstable type of green fluorescent protein (Gfp) tagged with a C-terminal extension, which is a target for tail-specific protease, was used as a reporter gene in Legionella pneumophila. To analyse Gfp expression in legionellae, transcriptional fusions of unstable gfp with the Legionella-specific icm (intracellular multiplication) promoters $\left(\mathrm{P}_{i c m S}, \mathrm{P}_{i c m T}\right.$ and $\mathrm{P}_{i c m \mathrm{Q}}$ ) were constructed. Infection studies using J774.1 macrophages as the host, and $L$. pneumophila strains carrying $\mathrm{P}_{i c m s}-g f p, \mathrm{P}_{i c m}-g f p$ and $\mathrm{P}_{i c m Q^{-}}$gfp fusions, indicated that the icmS, icmT and icmQ genes could be expressed intracellularly. Expression of $i \mathrm{cmS}$, icmT and icmQ genes in infected cells was examined by flow cytometry. Furthermore, fluorescent intracellular legionellae were detected directly by confocal microscopy. Real-time quantitative RT-PCR revealed the differences in the gene expression of $i \mathrm{cmS}$, and that of $i \mathrm{~cm} T$ and $i \mathrm{cmQ}$, during infection. Expression of $i \mathrm{cmS}$ was high in the late stage of infection, while that of $i \mathrm{~cm} T$ and $i c m Q$ was high in the early phase only. We show that unstable gfp is a useful reporter gene whose expression in legionellae can be followed in real-time, and that it allows analysis of promoter activities in legionellae and monitoring of the infection process.

\section{INTRODUCTION}

Legionella pneumophila is a ubiquitous Gram-negative bacterium that is normally found in fresh water and biofilms as an intracellular pathogen of protozoa (Abu Kwaik et al., 1998). The bacteria infect humans via aerosols, and replicate inside alveolar macrophages causing a severe form of pneumonia called Legionnaires' disease (Horwitz \& Silverstein, 1983).

The L. pneumophila icm (intracellular multiplication)/dot (defective organelle trafficking) genes, located in two chromosomal regions, are required for intracellular multiplication and host cell killing (Segal \& Shuman, 1998). Chromosomal region I harbours the genes icm V, W and $X$, and $\operatorname{dot} A, B, C$ and $D$ (Marra et al., 1992; Vogel et al., 1998), while region II contains the genes icm $T, S, R$, $Q, P, O, N, M, L, K, E, G, C, D, J, B$ and $F$ (Andrews et al., 1998; Horwitz, 1987; Segal \& Shuman, 1997; Vogel et al., 1998). Most of these genes are also required for intracellular growth in the protozoan host Acanthamoeba castellanii (Segal \& Shuman, 1999). The icm/dot system serves as a translocation system that delivers effector proteins to host cells (Nagai et al., 2002). However, there is not much information regarding regulation of L. pneumophila virulence, or expression of the $i \mathrm{~cm} /$ dot genes.
Investigating changes in gene expression is critical for understanding the adaptive responses of Legionella to environmental stress and during infection. Among the more commonly used reporter genes are those for the following proteins: chloramphenicol acetyltransferase, $\beta$ galactosidase, $\beta$-glucoronidase and luciferase. Green fluorescent protein (Gfp) obtained from the jellyfish Aequorea victoria has been used as an optimal bacterial reporter. Gfpmut $3^{*}$ is one of a number of Gfps; it is a very stable form of the protein, and gives off a very bright green fluorescence when expressed in bacteria. However, due to its long half-life, Gfpmut $3^{*}$ is not suitable as a reporter for studying real-time gene expression in individual cells. Furthermore, L. pneumophila strains carrying this type of Gfp did not multiply in the J774.1 macrophage cell line in our preliminary experiment. To expand the use of Gfp as a reporter protein, new variants have been constructed by insertion of a mutation into the chromophore, and by the addition of a short peptide sequence to the C-terminal end of intact Gfp (Cormack et al., 1996). The latter variant renders Gfp susceptible to the action of indigenous housekeeping proteases. The new Gfp variants should be useful for in situ studies of temporal gene expression. Therefore, to elucidate L. pneumophila gene expression during infection, the unstable type of Gfp was examined. 
Unstable Gfp variants and their application have been described for Escherichia coli, Pseudomonas putida and Mycobacterium smegmatis (Andersen et al., 1998; Blokpoel et al., 2003). It has been shown that specific C-terminal amino acid tails can make stable proteins that are susceptible to degradation by tail-specific proteases. This protein degradation system is based on ssrA-mediated tagging. The $s s r A$ transcript (known as 10Sa RNA or tmRNA) is a stable RNA molecule with tRNA properties and an internal reading frame encoding a 'tag' peptide. This peptide can be attached to the C-terminus of the protein, rendering it susceptible to specific proteases (Muto et al., 1998). The half-lives of tagged proteins in E. coli are dependent on the last 3 aa of the C-terminal tail (Keiler \& Sauer, 1996). Andersen et al. (1998) have shown that the half-lives of Gfp with four different amino acid tails vary between E. coli and P. putida, but are significantly shorter than those of stable Gfp. It has been shown that $L$. pneumophila has an ssrA gene (Chien et al., 2004). This indicates that $s s r A$-mediated tagging could be involved in protein degradation in this species.

After examination of the stability of Gfp variants in $L$. pneumophila, we elucidated that one of the Gfp variants, GfpAAV, could be used for measuring gene expression of $L$. pneumophila. This variant of unstable Gfp has been used for measuring the intracellular level of gene expression of the $i \mathrm{cmS}$, $\mathrm{icm} T$ and $i \mathrm{~cm} Q$ genes that are related to the type IV secretion system of $L$. pneumophila. These genes are specific for the type IV secretion system of L. pneumophila, and they have homologies with the type IV secretion system of $C$. burnetii only (Sexton et al., 2004; Zamboni et al., 2003). The $i \mathrm{~cm} T$ and $\mathrm{icmQ}$ genes are involved in the pore-forming process (Dumenil et al., 2004; Ninio et al., 2005). Moreover, icmQ and icmS genes are essential for the growth of $L$. pneumophila. However, it is not known when and how these genes are expressed. Thus, we tried to identify the moment when $i \mathrm{cmS}$, icm $T$ and $i \mathrm{~cm} Q$ genes are highly expressed during infection in J774.1 macrophage-like cells.

\section{METHODS}

Bacterial strains and culture media. L. pneumophila serogroup 1 strain AM511 was used for all experiments in this study. The organisms were grown on buffered charcoal yeast extract (BCYE) plates or in buffered yeast extract (BYE) broth, at $37^{\circ} \mathrm{C}$. E. coli strains were cultured on Luria-Bertani (LB) agar plates, or in LB broth at $37{ }^{\circ} \mathrm{C}$. All the bacterial strains used in this study are described in Table 1. As required, antibiotics were added to the media at the following concentrations: $25 \mu \mathrm{g}$ kanamycin $\mathrm{ml}^{-1}$ for L. pneumophila; $30 \mu \mathrm{g}$ kanamycin $\mathrm{ml}^{-1}$ and $50 \mu \mathrm{g}$ ampicillin $\mathrm{ml}^{-1}$ for E. coli.

Cell culture. J774.1 cells (JCRB0018) derived from mouse macrophage-like cells were cultured in RPMI 1640 medium (Sigma) supplemented with $10 \%$ fetal bovine serum (Gibco).

\section{Plasmid construction}

The plasmids used in this study are listed in Table 2.

NotI fragments $(2 \mathrm{~kb})$ containing $\mathrm{P}_{A I / 04 / 03}$-RBSII-gfpmut $3^{*}-\mathrm{T}_{0}-\mathrm{T}_{1}$, $r r n B P 1:: g f p(\mathrm{AGA})-\mathrm{T}_{0}-\mathrm{T}_{1}, \mathrm{P}_{A I / 04 / 03^{-}}$RBSII- $g f p(\mathrm{LAA})-\mathrm{T}_{0}-\mathrm{T}_{1}, \mathrm{P}_{A I / 04 / 03^{-}}$ RBSII- $g f p(A A V)-\mathrm{T}_{0}-\mathrm{T}_{1}$ or $\mathrm{P}_{A I / 04 / 03}-\mathrm{RBSII}-g f p(\mathrm{ASV})-\mathrm{T}_{0}-\mathrm{T}_{1}$ (in which RBSII is the synthetic ribosome-binding site, $\mathrm{T}_{0}$ is the transcriptional terminator from phage $\lambda$, and $T_{1}$ is the transcriptional terminator from the $r r B$ operon of $E$. coli) were taken from plasmids pJBA27, pJBA45, pJBA110, pJBA112 and pJBA113, respectively. The fragments were inserted into the NotI site of the pOKM66EH vector under a lacI ${ }^{\mathrm{q}}$ IPTG-inducible promoter to create pTOM1, pTOM2, pTOM3, pTOM4 and pTOM5, which differ only in the sequence of the $g f p$ gene (Fig. 1). The resulting plasmids were introduced via electroporation into the L. pneumophila AM511 strain, using a Gene Pulser (Bio-Rad Laboratories).

Design of the icmS-gfp(AAV), icmT-gfp(AAV) and icmQ-gfp(AAV) fusions. The recombinant plasmid pET-23a-d $(+)+3$ was generated by inserting a NotI fragment from pJBA112 plasmid, and digesting with $K p n \mathrm{I}$ and $S p h \mathrm{I}$ enzymes to take out $\mathrm{P}_{A 1 / 04 / 03}$, the LacI-repressible lac promoter and RBSII of the Gfp. The Legionella-specific icmS, icm T and icmQ promoters were amplified from the chromosome DNA of L. pneumophila AM511 by PCR. The nucleotide sequences of the oligonucleotides were as follows. icmS (GenBank accession number AY543435): forward primer, 5'-GGGGTACCCCTCCTCTCATTACA-

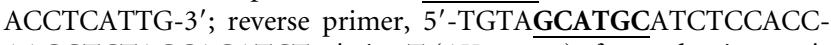
AAGGTCTAGCAGATCT-3'. icm T (AY543439): forward primer, 5' GGGGTACCCCGCGTTGTTCAGATACAGTATAAGGGC-3'; reverse primer, 5'-TGTAGCATGCTTAAACCTCAAAAAATCATCCTTT-3'. icmQ (AY543402): forward primer, 5'-GGGGTACCCCGAACATTATGGTTTCACTCTCCC-3'; reverse primer, 5' -GTAGCATGCCTTCAATACTTATGGGAACCAAGAATTAGGG-3'. To facilitate cloning, the $K p n \mathrm{I}$ and $S p h \mathrm{I}$ restriction sites (underlined) were introduced into the forward and reverse primers, respectively. Relevant restriction sites are underlined. PCR was performed with 34 cycles of denaturation for $1 \mathrm{~min}$ at $96{ }^{\circ} \mathrm{C}$, annealing for $1 \mathrm{~min}$ at $55{ }^{\circ} \mathrm{C}$, and extension for $1 \mathrm{~min}$ at $72{ }^{\circ} \mathrm{C}$. Finally, the resulting $480 \mathrm{bp}$ DNA fragments containing $\mathrm{P}_{i c m s}, \mathrm{P}_{i c m T}$ and $\mathrm{P}_{i c m Q}$ were cloned into the KpnI/SphI site of plasmid pET-23a-d $(+)+3$. Then, the fragments $\mathrm{P}_{i c m s}+g f p(\mathrm{AAV})-\mathrm{T}_{0}-\mathrm{T}_{1}, \quad \mathrm{P}_{i c m T}+g f p(\mathrm{AAV})-\mathrm{T}_{0}-\mathrm{T}_{1}$ and $\mathrm{P}_{i c m Q}+$ $g f p(\mathrm{AAV})-\mathrm{T}_{0}-\mathrm{T}_{1}$ were taken out by NotI digestion, and cloned into

Table 1. Bacterial strains used in this study

\begin{tabular}{|c|c|c|}
\hline Strain & Relevant genotype and characteristics & Reference or source \\
\hline \multicolumn{3}{|c|}{ L. pneumophila } \\
\hline AM511 & $\operatorname{Str}^{\mathrm{r}} \operatorname{Res}^{-} \mathrm{Mod}^{+}$derivative of Philadelphia-1 strain & Marra \& Shuman (1989) \\
\hline \multicolumn{3}{|c|}{ ( } \\
\hline DH $5 \alpha$ & $\begin{array}{l}\text { supE44 hsdR17 recA1 endA1 gyrA96 relA1 thi } \Delta(\text { lac-proAB }) \mathrm{F}^{\prime}(\text { traD36 proAB } \\
\left.\text { lacl }^{+} \text {lacZ } \Delta M 15\right)\end{array}$ & Invitrogen \\
\hline JM 109 & $\begin{array}{l}\text { sup E44 hsdR17 recA1 endA1 gyrA96 relA1 thi } \Delta(\text { lac-proAB }) \mathrm{F}^{\prime}(\text { traD36 proAB } \\
\text { lacl }^{+} \text {lacZDM15) }\end{array}$ & Invitrogen \\
\hline
\end{tabular}


Table 2. Plasmids used and constructed in this study

gfpmut3 ${ }^{\star}$, gene encoding Gfp (S2R, S65G, S72A) [referred to by Andersen et al. (1998) as Gfpmut3*]; gfp(AGA, LAA, AAV, ASV), gene encoding Gfp with destabilizing C-terminal tails AGA, LAA, AAV or ASV, respectively; $\mathrm{T}_{0}$, transcriptional terminator from $\lambda$ phage; $\mathrm{T}_{1}$, transcriptional terminator from the $r r B$ operon of $E$. coli.

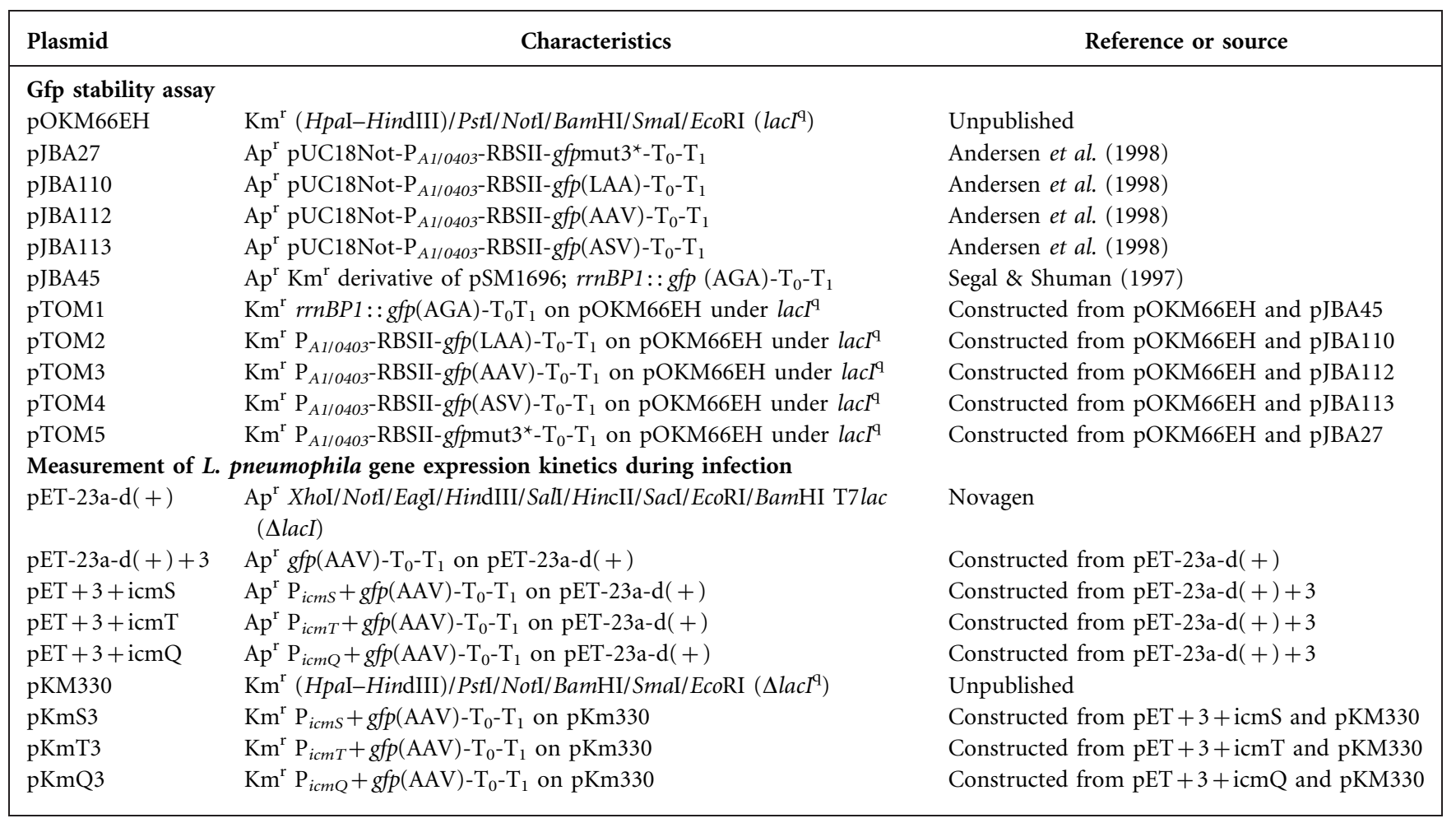

the NotI site of the pKM330 (Fig. 2). The resulting plasmids (pKmS3, $\mathrm{pKmT3}$ and $\mathrm{pKmQ3}$ ) were transformed into the L. pneumophila AM511 strain using an electroporation Gene Pulser (Bio-Rad Laboratories), and they were used for measuring Legionella gene expression kinetics.
Quantification of Gfp fluorescence, and its degradation in liquid cultures. L. pneumophila AM511 carrying an insertion of $g f p$ cassettes was grown at $37^{\circ} \mathrm{C}$ on BCYE agar for 2 days. Then, AM511 strains (single colonies) were grown to stationary phase in BYE

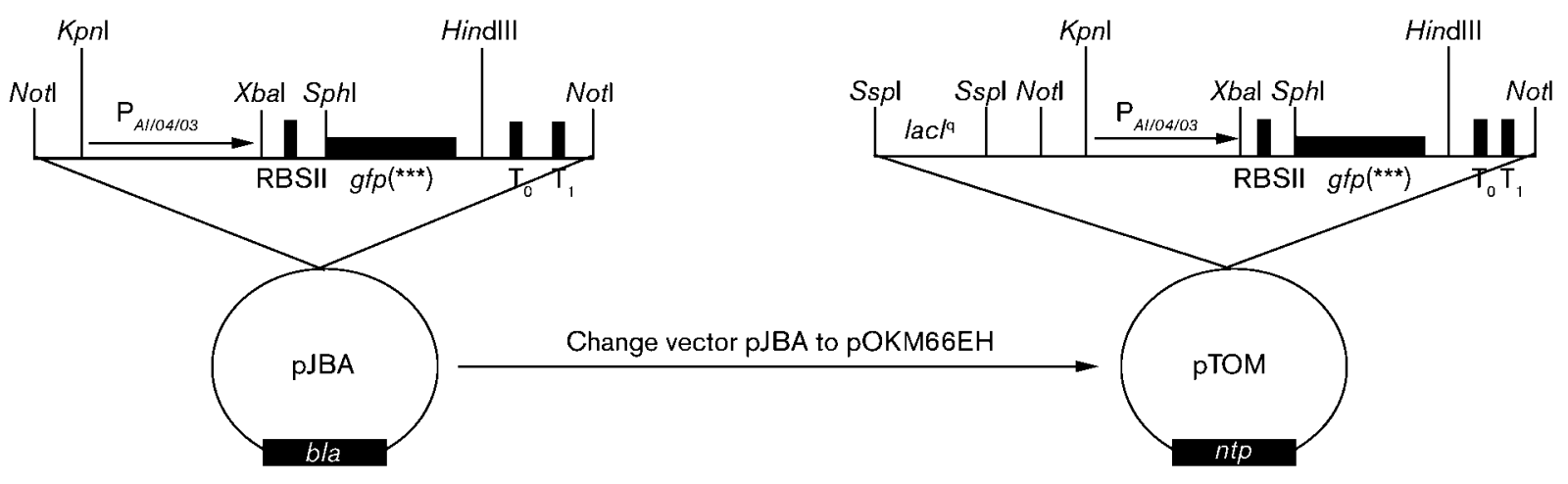

Fig. 1. Schematic drawing of vectors used for the Gfp stability assay. A $2 \mathrm{~kb}$ Notl fragment, containing different forms of $g f p$ on pJBA plasmids, was cloned into the $\mathrm{pOKM} 66 \mathrm{EH}$ vector downstream of $/ \mathrm{ac} /{ }^{q}$, which is an IPTG-inducible promoter, and constructed pTOM plasmids were used for the Gfp stability assay. The pJBA plasmids were pJBA27, pJBA45, pJBA110, pJBA112 and pJBA113 plasmid groups, carrying gfpmut3*, gfp(AGA), gfp(LAA), gfp(AAV) and gfp(ASV), respectively. The pTOM plasmids were pTOM1, pTOM2, pTOM3, pTOM4 and pTOM5, resulting in plasmids carrying $g f p(A G A), g f p(L A A)$, $g f p(A A V), g f p(A S V)$ and $g f p m u t 3^{*}$, respectively. $\mathrm{P}_{A 1 / 0403}$, Lacl-repressible lac promoter; RBSIl, synthetic ribosome-binding site; $\mathrm{T}_{0}$, transcriptional terminator from phage $\lambda ; \mathrm{T}_{1}$, transcriptional terminator from the $r$ r operon of $E$. coli; gfp $\left.{ }^{(\star \star}\right)$, gene encoding Gfp with destabilizing C-terminal tail $\left.{ }^{\star \star \star}\right)$. 


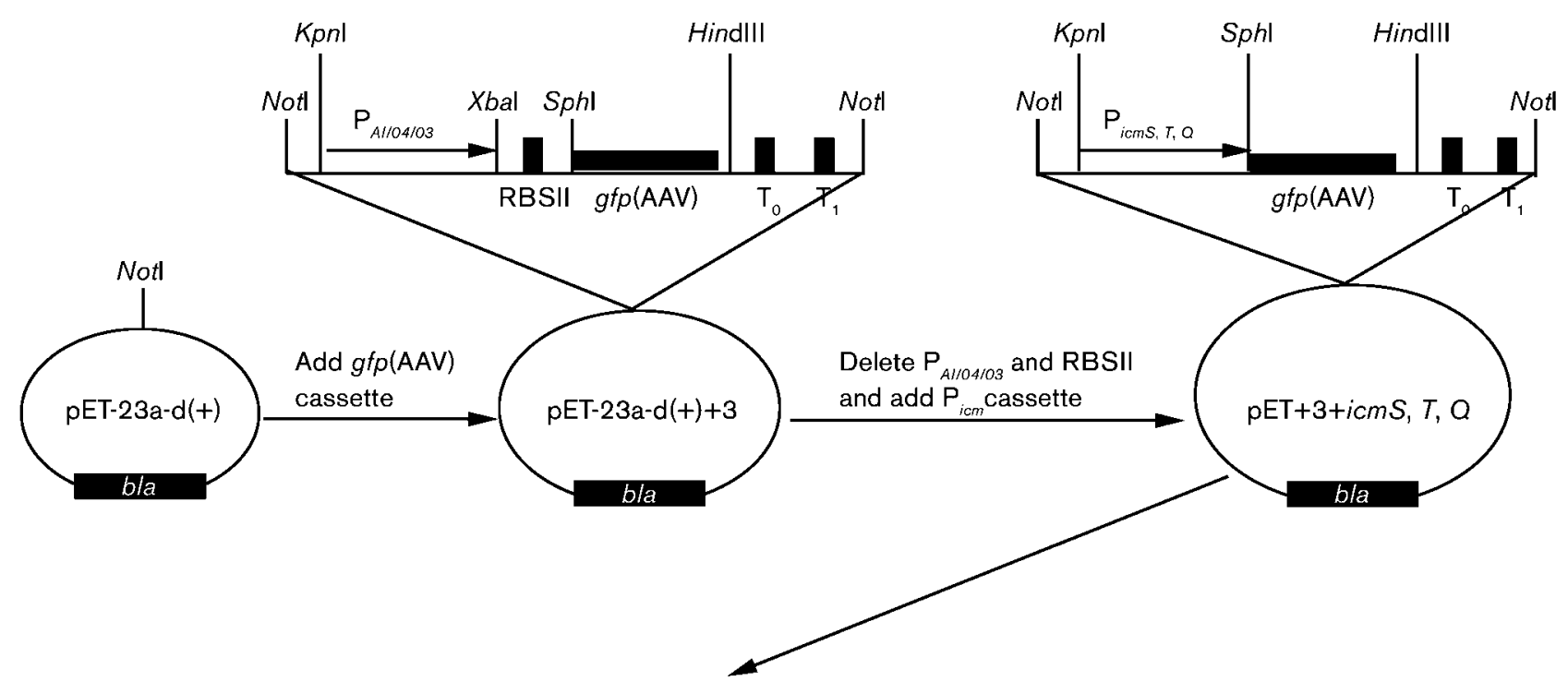

Change vector $\mathrm{pET}-23 \mathrm{a}-\mathrm{d}(+)$ to $\mathrm{pKM} 330$
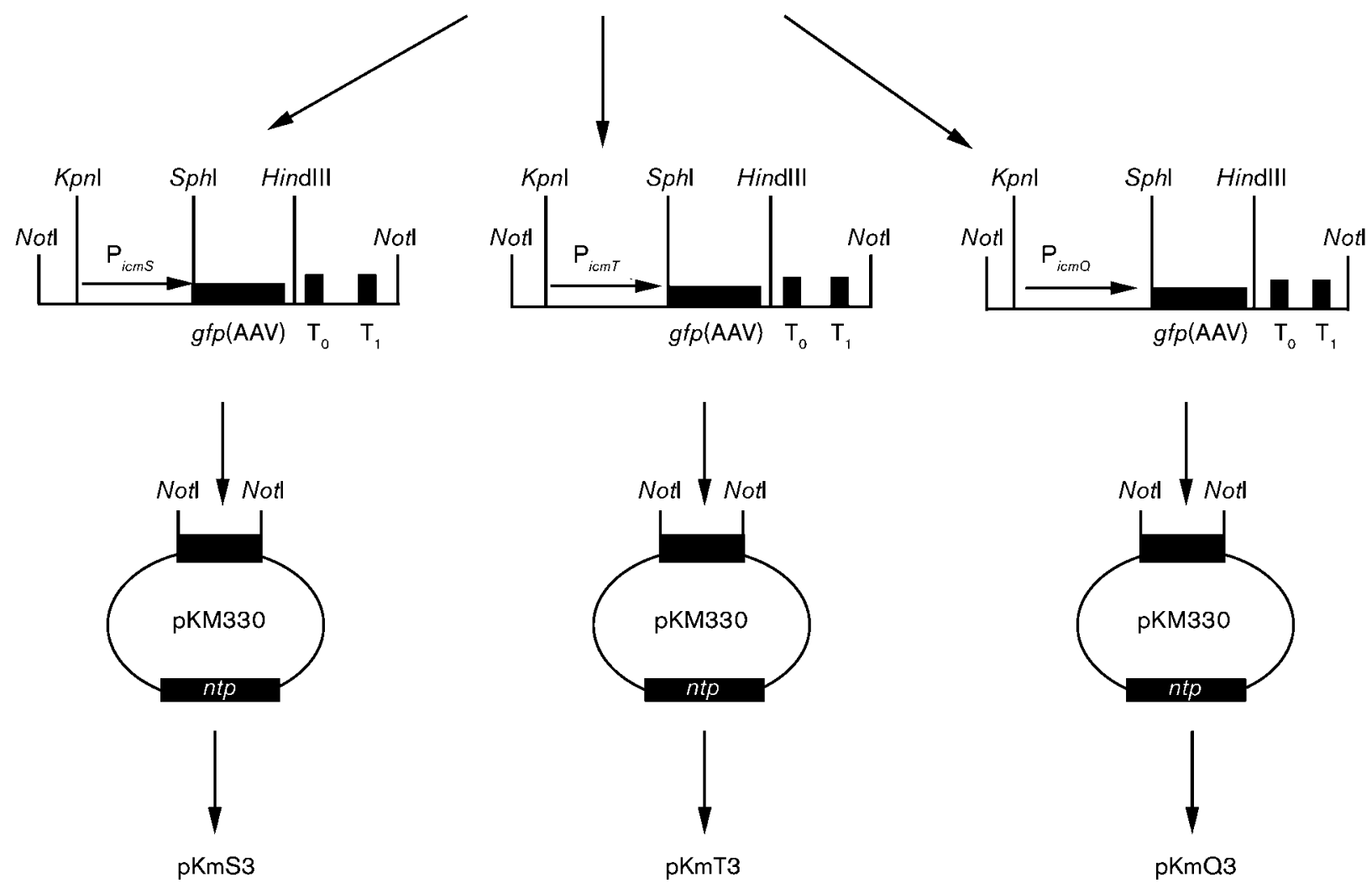

Fig. 2. Schematic drawings of the transcriptional fusion vector carrying the gfp(AAV) gene under the control of $L$. pneumophila $i c m S, i c m T$ and icmQ gene promoters. pET-23a-d(+) vector is not expressed in L. pneumophila; it was used for cloning manipulations only, because it has appropriate restriction enzyme sites. pKM330 vector was expressed in $L$. pneumophila, and was used as a carrier for transcriptional fusion. bla, ampicillin-resistance gene; ntp, kanamycin-resistance gene; $P_{A 1 / 0403}$, Laclrepressible lac promoter; RBSIl, synthetic ribosome-binding site; $\mathrm{P}_{i c m s}, \mathrm{P}_{i c m T}$ and $\mathrm{P}_{i c m Q}$, icmS, icmT and icmQ promoters from L. pneumophila, respectively; gfp(AAV), gene encoding Gfp, with destabilizing C-terminal tail (AAV); $T_{0}$, transcriptional terminator from phage $\lambda ; T_{1}$, transcriptional terminator from the $\operatorname{rr} B$ operon of $E$. coli. 
medium supplemented with $25 \mu \mathrm{g}$ kanamycin $\mathrm{ml}^{-1}$. During the next step, the culture was diluted 1 in 30 in BYE broth supplemented with $25 \mu \mathrm{g}$ kanamycin $\mathrm{ml}^{-1}$ and $1 \mathrm{mM}$ IPTG, followed by continuous growth until late exponential phase at $37^{\circ} \mathrm{C}$, with shaking (100 r.p.m.). The cells were harvested by centrifugation at $2300 \mathrm{~g}$ for $10 \mathrm{~min}$, and washed three times in PBS. The cells were resuspended in PBS to a concentration of approximately 0.6 at $\mathrm{OD}_{600}$, and re-incubated at $37{ }^{\circ} \mathrm{C}$ with shaking (100 r.p.m.); samples were taken in $0.2 \mathrm{ml}$ aliquots at hourly intervals for $7 \mathrm{~h}$. Green fluorescence was measured with a Wallac 1420 ARVOsx DELFIA Multilabel counter (PerkinElmer) set at an excitation wavelength of $485 \mathrm{~nm}$, and an emission detection wavelength of $535 \mathrm{~nm}$. All samples were taken in triplicate.

In vitro phagocytosis, and intracellular growth assay. In vitro phagocytosis was done as follows. L. pneumophila strains were grown in BYE broth until the early stationary phase. Approximately $2 \times 10^{9}$ bacteria $\mathrm{ml}^{-1}$ were pelleted, and resuspended and diluted $(1: 1000)$ in RPMI 1640 tissue culture medium. The bacteria were then added to J774.1 cells $\left(2 \times 10^{5}\right.$ cells per well $)$ in 24 -well dishes to give a m.o.i. of about 10 . The infected cells were incubated at $37{ }^{\circ} \mathrm{C}$ under $5 \% \mathrm{CO}_{2}$ for $1 \mathrm{~h}$, and washed three times with PBS to remove extracellular and non-adherent bacteria. To measure bacterial internalization, $1 \mathrm{ml}$ sterile distilled water was added to the wells to release intracellular bacteria from the host cells, and the number of c.f.u. was determined by plating dilutions on BCYE agar plates. To each of the remaining wells, $0.5 \mathrm{ml}$ fresh tissue culture medium was added, and the culture was continued. At $24 \mathrm{~h}$ intervals, the intracellular and extracellular bacteria in each well were combined, and the total number of c.f.u. was determined by plating the dilutions on BCYE agar plates.

Electron microscopy. To provide confirmation of the results of the intracellular growth assay, J774.1 macrophages were infected with the wild-type L. pneumophila AM511, L. pneumophila AM511 carrying gfpmut $3^{\star}$, and L. pneumophila AM511 with icm-gfp(AAV) fusions. In vitro phagocytosis was performed as described above, using a $50 \mathrm{ml}$ conical tube and a m.o.i. of 10 . At $20 \mathrm{~h}$ post-infection, the cells were fixed, and processed for electron microscopy, as previously described (Wai et al., 1998). Briefly, infected macrophages were fixed with $2 \%$ glutaraldehyde, and then $1 \% \mathrm{OsO}_{4}$, and then dehydrated with ethanol, and embedded in Epon. Ultrathin sections were stained with uranyl acetate, followed by lead citrate, and examined by electron microscopy in a JEM 2000EX instrument (JEOL).

Flow cytometric analysis. In vitro phagocytosis was performed as described above, using $9 \mathrm{~cm}$ Petri dishes (Eiken Chemical) and a m.o.i. of 10. J774.1 cells did not adhere to the Petri dishes, and the floating infected J774.1 cells were analysed directly by a FACScan flow cytometer (Becton Dickinson). To permeabilize macrophages, saponin was added at a final concentration of $0.1 \%$.

The flow cytometric analysis was carried out with the following detector settings: FSC, E01; SSC, 458; and FL1, 600; using logarithmic gains. Quadrant location was set at FL1 ( $y$-axis), 229; FSC ( $x$-axis), 250; and the cells infected with L. pneumophila containing icmS$g f p(\mathrm{AAV}), i c m T-g f p(\mathrm{AAV})$ and $i c m Q-g f p(\mathrm{AAV})$ were counted in the upper-right area. The FL1-FSC plot was analysed using BD CellQuest Pro (v2.6.8, f7b; BD Biosciences).

RNA isolation from intracellular bacteria. In vitro phagocytosis was performed as described above, using a $150 \mathrm{~cm}^{2}$ culture flask and a m.o.i. of 10. The infected cells were incubated at $37{ }^{\circ} \mathrm{C}$ under $5 \%$ $\mathrm{CO}_{2}$ for $1 \mathrm{~h}$, and washed three times with PBS to remove extracellular bacteria. Cells were lysed directly in a $150 \mathrm{~cm}^{2}$ culture flask by adding $20 \mathrm{ml}$ TRIzol Reagent (Invitrogen), and shaking for about $5 \mathrm{~min}$ at room temperature, and then they were transferred to a $50 \mathrm{ml}$ tube for incubation (overnight at $4{ }^{\circ} \mathrm{C}$ ). Chloroform was added to induce separation of the organic and aqueous phases, and the phases were separated by centrifugation $\left(15 \mathrm{~min}, 4{ }^{\circ} \mathrm{C}, 14000 \mathrm{~g}\right)$. RNA was precipitated using 2-propanol, and samples were centrifuged for $10 \mathrm{~min}$ at $4{ }^{\circ} \mathrm{C}$ and $14000 \mathrm{~g}$. Pellets were washed with $75 \%$ ethanol, which was removed after further centrifugation $\left(5 \mathrm{~min}, 4{ }^{\circ} \mathrm{C}\right.$, $14000 \mathrm{~g}$ ). The pellets were dried, and dissolved in $20 \mu \mathrm{l}$ RNase-free water. RNA was treated with DNase I (Roche Diagnostics) for $1 \mathrm{~h}$ to ensure complete DNA removal.

Real-time RT-PCR. The oligonucleotides of the forward and reverse primers, and the TaqMan probe for L. pneumophila icmS, icmT and $i \mathrm{~cm} Q$, were designed using Primer Express software (Applied Biosystems). The nucleotide sequences of the oligonucleotides were as follows. icmS (GenBank accession number AY543435): forward primer, 5' ${ }^{\prime}$-ATTGCCAAGAGAGCGGATCAA-3'; reverse primer, 5' CGTCATAAGTTGCTCCCAAACCATA-3'; reporter probe, CCCAAACACAAGGAACACA. icm $T$ (GenBank accession number AY543439): forward primer, $5^{\prime}$-TGGTTTCACTGTCCCGGTTTT-3'; reverse primer, 5' -CCACCAAGGTCTAGCAGATCTAAC-3'; reporter probe, CTGGCTCAGAAGTTTTT. icmQ (GenBank accession number AY543402): forward primer, 5'-CCGCTAGTCAGGCCAAGTTAA-3'; reverse primer, $5^{\prime}$-ACCACTCCTTAAGGCAATTCGATT-3'; reporter probe, AAGCAGAGTCTCATCTTGCA. Expression of mRNA for $L$. pneumophila icmS, icmT and icmQ was measured in J774.1 cells, and the total RNA of samples was measured by real-time PCR, using TaqMan gene expression assays on an ABI PRISM 7000 sequence detection system (Applied Biosystems). A $5 \mu \mathrm{g}$ sample of the total RNA of each sample was used to generate cDNA using the ABI High Capacity cDNA Archiving kit (Applied Biosystems), and real-time PCR reactions were carried out using the manufacturer's protocol. On each plate, an endogenous control gene (16S rDNA) and a notemplate control were also run in duplicate.

Laser scanning confocal microscopy. In vitro phagocytosis was performed as described above using RPMI 1640 medium without phenol red (Sigma), and supplemented with $10 \%$ fetal bovine serum (Gibco), in a $35 \mathrm{~mm}$ glass-base dish (Iwaki), at a m.o.i. of 10. Confocal fluorescence and time-lapse images were obtained with an LSM 510 META laser scanning confocal microscope (Carl Zeiss).

\section{RESULTS}

\section{Stability of tagged Gfp variants in L. pneumophila}

The kinetics of stability of the different forms of the Gfp (Gfpmut $3^{*}$ and the four unstable variants) was investigated. IPTG was added to exponentially growing cultures of $L$. pneumophila containing the plasmids pTOM1, pTOM2, pTOM3, pTOM4 and pTOM5 (Table 2). Stability of Gfpmut $3^{*}$ and the four variants was measured as relative fluorescence against time, after the removal of IPTG by washing. The time course of degradation of the different types of Gfp samples is shown in Fig. 3. All of the four variants, Gfp(AGA), Gfp(ASV), Gfp(LAA) and Gfp(AAV), were fluorescent in L. pneumophila, and, $7 \mathrm{~h}$ after the removal of IPTG, they exhibited relative fluorescence values of 75, 50, 48 and $8 \%$, respectively. Fluorescence measurements for all the Gfp variants were compared with a value of $90 \%$ for Gfpmut $3{ }^{*}$. From the results, one of the tagged Gfp variants, Gfp(AAV) type, which had the shortest half-life, was chosen for measurement of $L$. pneumophila intracellular gene expression. 


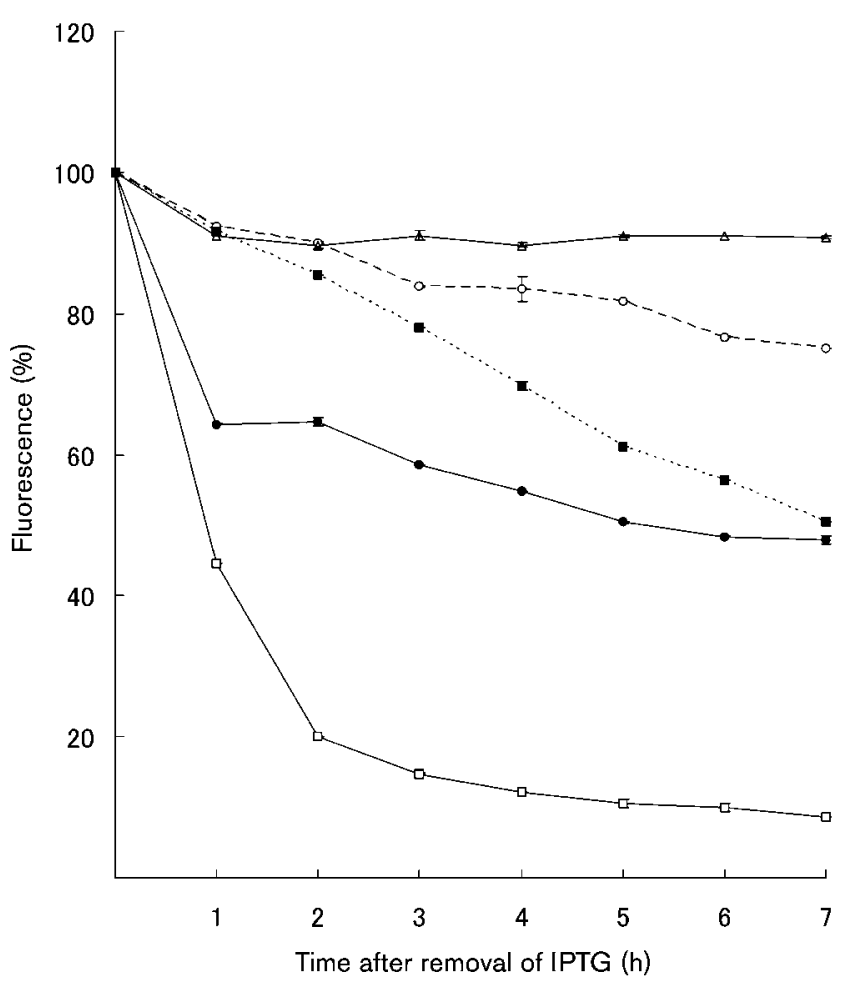

Fig. 3. Stability of tagged Gfp variants in L. pneumophila cells. Expression was induced by growth of the AM511 strains, carrying pTOM plasmids, in the presence of $1 \mathrm{mM} \mathrm{IPTG.} \mathrm{Expression} \mathrm{from}$ the $P_{A 1 / 0403}$ promoter was then switched off by removal of the IPTG by washing in PBS (time ' $O$ '), and the fluorescence was measured at hourly intervals using a Multilabel counter. The fluorescence at time 0 was set at $100 \%$, following subtraction of the background readings obtained from a non-fluorescent control. These data are representative of at least three independent experiments performed in triplicate. Error bars indicate the standard deviations; the absence of error bars indicates very small standard deviations that could not be displayed. $\bigcirc$, pTOM1 (gfpAGA); •, pTOM2(gfpLAA); $\square$, pTOM3(gfpAAV); , pTOM4(gfpASV) and $\triangle$, pTOM5(gfpmut3*).

\section{Intracellular growth of $L$. pneumophila containing stable and unstable Gfp}

Intracellular multiplication of $L$. pneumophila strains in J774.1 macrophages was examined. The wild-type $L$. pneumophila AM511 strain, and strains carrying gfpmut $3^{*}$, $\mathrm{P}_{i c m s^{-}} g f p(\mathrm{AAV}), \quad \mathrm{P}_{i c m T^{-}} g f p(\mathrm{AAV})$ and $\mathrm{P}_{i c m Q^{-}} g f p(\mathrm{AAV})$ fusions, were used to infect J774.1 cells. The number of bacterial c.f.u. was determined daily for 3 days. The wildtype, and strains carrying $\mathrm{P}_{i c m^{-}} g f p(\mathrm{AAV})$ fusions, multiplied over 100 -fold during the incubation period of 3 days. Strains with $g f p m u t 3 *$ showed a 10 -fold increase after 1 day of incubation, but they did not grow during the following 2 days of incubation (Fig. 4).

To provide confirmation of the results of the intracellular growth assay, J774.1 macrophages were infected with the wild-type L. pneumophila strain, the strain carrying

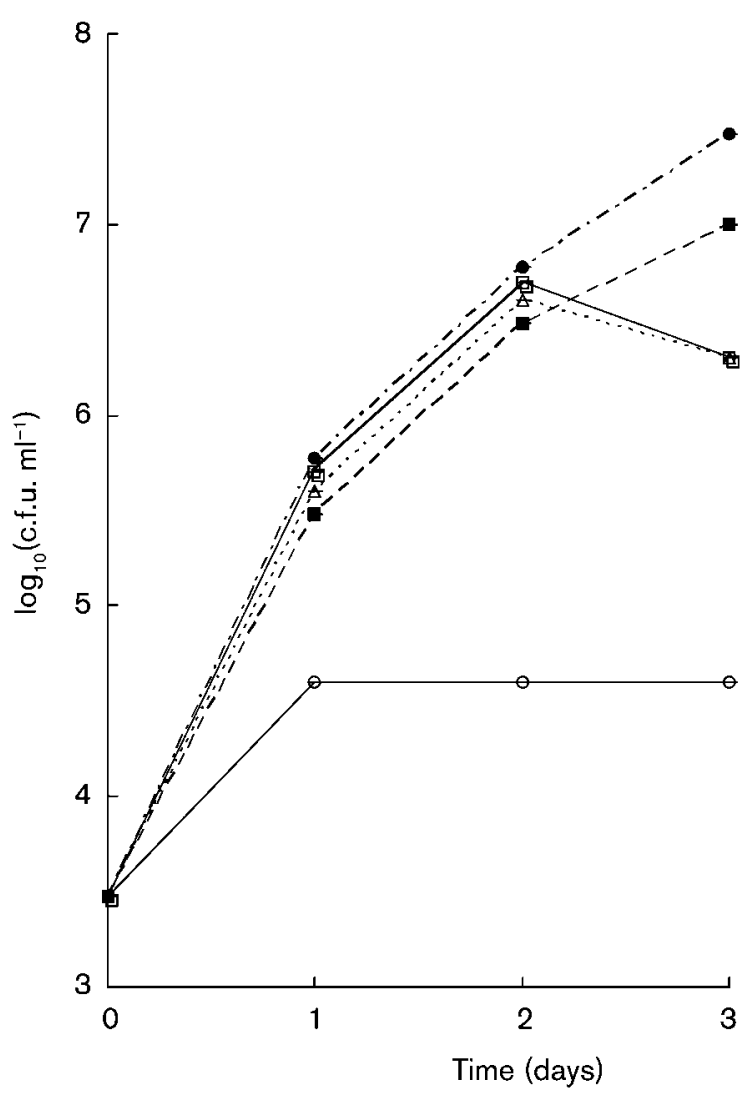

Fig. 4. Intracellular growth of $L$. pneumophila carrying stable and unstable types of Gfp within J774.1 mouse macrophages. These data are representative of at least three independent experiments performed in triplicate. Error bars indicate the standard deviations; the absence of error bars indicates very small standard deviations that could not be displayed. $\bullet$, Wild-type L. pneumophila AM511; $\bigcirc$, L. pneumophila carrying gfpmut3*; $\mathbf{\square}$, L. pneumophila with $\mathrm{P}_{i c m S^{-}}$ffp(AAV) fusion; $\square$, L. pneumophila with $\mathrm{P}_{i c m T}-g f p(\mathrm{AAV})$ fusion; $\triangle$, L. pneumophila with $\mathrm{P}_{i c m O^{-}} g f p(\mathrm{AAV})$ fusion.

$g f p m u t 3^{*}$, and strains with $\mathrm{P}_{i c m}-g f p(\mathrm{AAV})$ fusions, and multiplication was confirmed using transmission electron microscopy (Fig. 5). At $20 \mathrm{~h}$ post-infection, the wild-type (Fig. 5a) and L. pneumophila carrying $\mathrm{P}_{i c m}-g f p(\mathrm{AAV})$ (Fig. 5c) had replicated in the phagosomes, while $L$. pneumophila carrying gfpmut $3^{\star}$ did not multiply in J774.1 cells (Fig. 5b).

\section{Flow cytometric analysis of intracellular gene expression}

We compared the expression levels of three icm-gfp fusions at $0,3,6,20,21,22$ and $23 \mathrm{~h}$ after infection, using the FACScan flow cytometer (Fig. 6). The expression levels of the genes during infection were found to be different from one another. At $0 \mathrm{~h}$ of infection, expression of $i \mathrm{cmS}$, icm T and $i \mathrm{cmQ}$ was high, particularly that of $i \mathrm{~cm} S$ and $i \mathrm{cmQ}$. At $3 \mathrm{~h}$, all the genes were expressed at high levels, and expression of $i \mathrm{~cm} T$ was higher than that at $0 \mathrm{~h}$. At $6 \mathrm{~h}$, 

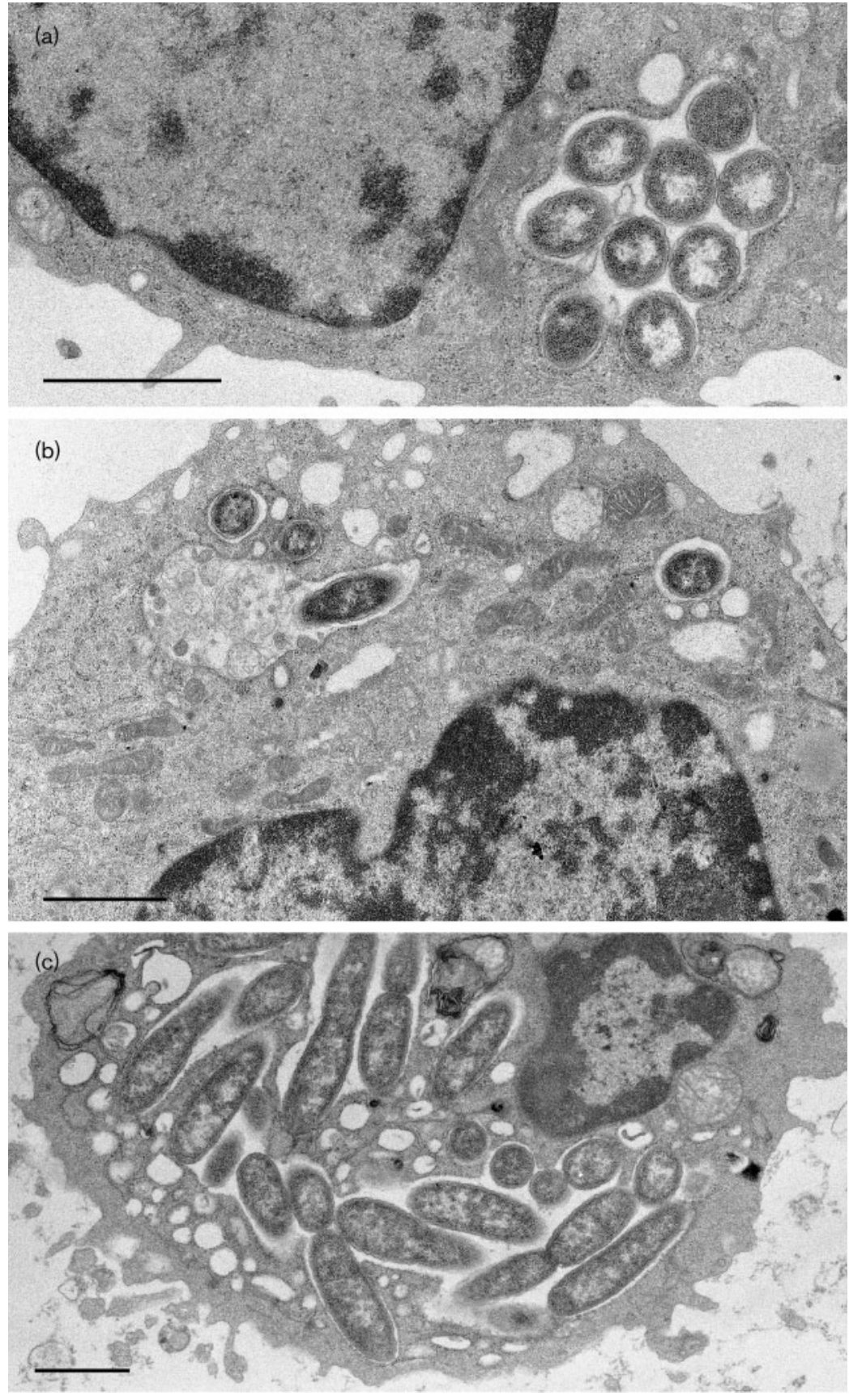

Fig. 5. Electron microscopy of intracellular $L$. pneumophila carrying stable and unstable types of Gfp. J774.1 mouse macrophages infected with wild-type L. pneumophila (a), L. pneumophila carrying gfpmut3*(b), and $L$. pneumophila carrying $\mathrm{P}_{i c m s}-g f p(\mathrm{AAV})$ (c), at $20 \mathrm{~h}$ after infection. Bar, $1.0 \mu \mathrm{m}$. expression of the icmS gene showed a further increase, while expression of icm $T$ and $i c m Q$ genes showed a decrease. From 20 to $23 \mathrm{~h}$ after infection, expression of $i \mathrm{~cm} T$ and $i \mathrm{~cm} Q$ genes was at a low level, whereas the expression of $i \mathrm{cmS}$ showed a gradual increase.

\section{Real-time quantitative RT-PCR}

Differences in gene expression during infection were determined at the transcriptional level using real-time RT-PCR (Fig. 7). mRNA was purified from bacteria growing intracellularly. At $0 \mathrm{~h}$ of infection, the expression levels of all three genes were observed to be very low. However, from $3 \mathrm{~h}$ after infection, the transcriptional level of the icmS gene significantly increased, and the transcriptional levels of the icmT and icmQ genes were higher compared with the levels at $0 \mathrm{~h}$, but they were still relatively low.

\section{Visual detection of fluorescent $L$. pneumophila during interaction with J774.1 cells}

To investigate whether fluorescent intracellular legionellae could be detected directly, L. pneumophila AM511 strains 


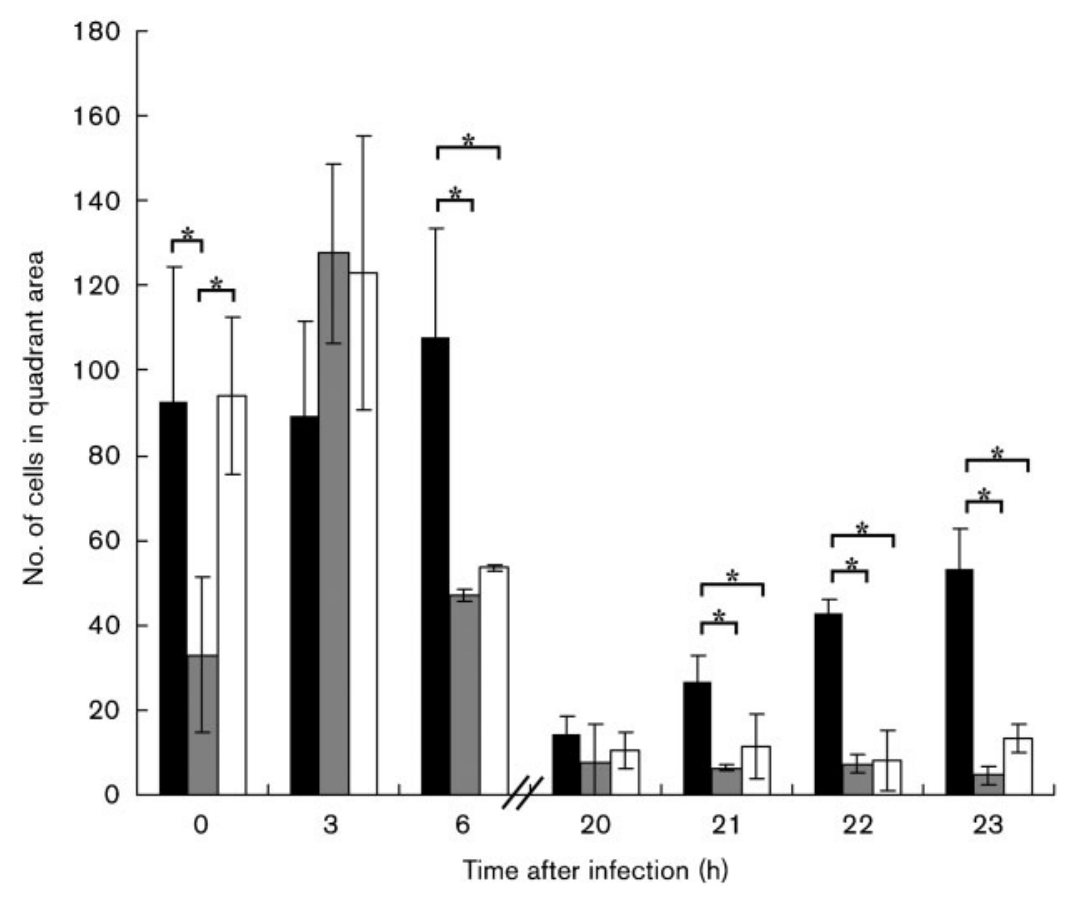

Fig. 6. Expression of icms, icm T and icm $\mathrm{C}$ genes during infection in J774.1 cells. Flow cytometric analysis of J774.1 macrophages infected with the unstable Gfp(AAV)-tagged $L$. pneumophila strain AM511 fusions [black bar,

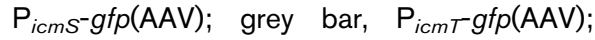
white bar, $\mathrm{P}_{i c m} \mathrm{Q}^{-} g f p(\mathrm{AAV})$ ] was carried out at different time points of infection. The cytofluorometric analysis was performed directly on $10^{4} \mathrm{J774.1}$ cells. Extracellular bacteria were distinguished from J774.1 cells by appropriate setting of thresholds with forward scatter and side scatter parameters. Non-infected cells of J774. 1 were used as a negative control. These data are representative of at least three independent experiments performed in triplicate. Error bars indicate the standard deviations. Statistical analysis was performed using SPSS 15.0 Brief Guide $t$ test to compare the differences between samples, and $P$ values of $<0.05$ were considered statistically significant $\left({ }^{\star}\right)$.

carrying the $\mathrm{P}_{i c m s^{-}} g f \mathrm{p}(\mathrm{AAV}), \mathrm{P}_{i c m T^{-}} g f p(\mathrm{AAV})$ or $\mathrm{P}_{i c m Q^{-}}$ $g f p(\mathrm{AAV})$ construct were used to infect J774.1 cells. Infected J774.1 cells were then observed for $24 \mathrm{~h}$ by laser scanning confocal microscopy. As shown in Fig. 8, the $\mathrm{icm}$ genes were expressed during infection, and this was observed as fluorescence. The icmS promoter was highly

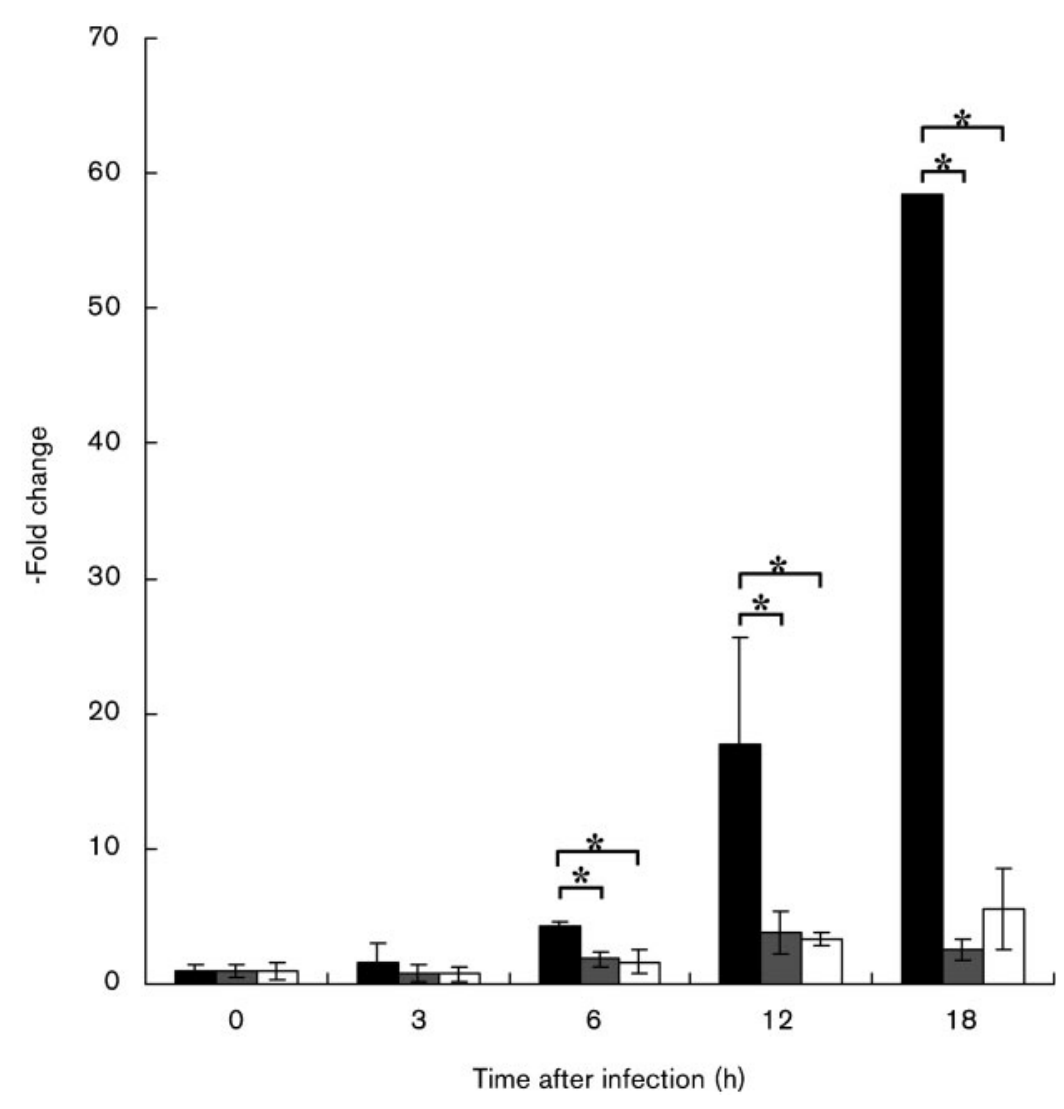

Fig. 7. Quantitative real-time RT-PCR. Gene expression of $L$. pneumophila during infection was confirmed at the transcriptional level using real-time PCR. Results are shown as fold change in which the value of icmS (black bar), icmT (grey bar) and icm (white bar) at $\mathrm{O} \mathrm{h}$ is $1 \pm$ SD of three independent experiments at 0 , $3,6,12$ and $18 \mathrm{~h}$ of infection. Samples were taken in triplicate. Statistical analysis was performed using SPSS 15.0 Brief Guide $t$ test to compare the differences between samples, and $P$ values of $<0.05$ were considered statistically significant $\left(^{*}\right)$. 


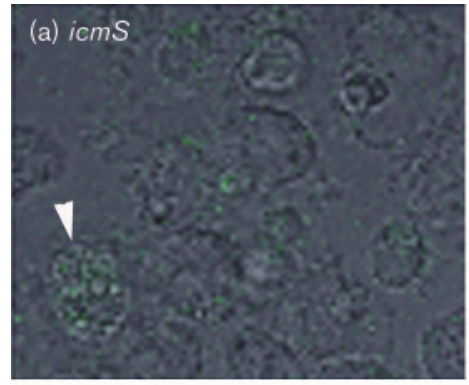

$20 \mathrm{~h}$ after infection

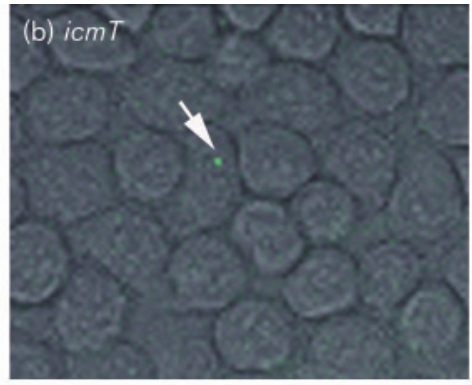

$2 \mathrm{~h}$ after infection

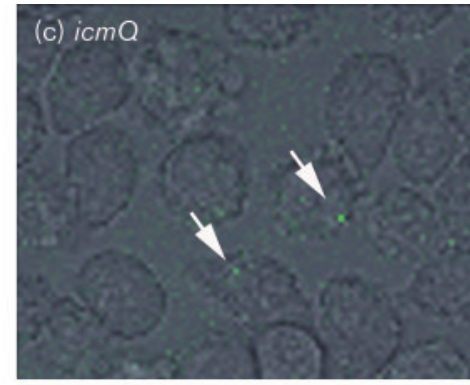

$1 \mathrm{~h}$ after infection

Fig. 8. Detection of fluorescent intracellular L. pneumophila. Laser scanning confocal microscopy of J774.1 cells infected with the unstable Gfp-tagged L. pneumophila strains AM511 $\mathrm{P}_{i c m S^{-}} g f p(\mathrm{AAV})(\mathrm{a}), \mathrm{P}_{i c m}$ T $g f p(\mathrm{AAV})(\mathrm{b})$, and $\mathrm{P}_{i c m 0^{-}} g f p(\mathrm{AAV})$ (c).

active at $20 \mathrm{~h}$ after infection (Fig. 8a), while the icm T promoter was active during the first $5 \mathrm{~h}$, most notably at $2 \mathrm{~h}$ after infection (Fig. $8 \mathrm{~b}$ ). icm $\mathrm{Q}$ was active at $1 \mathrm{~h}$ after infection (Fig. 8c).

\section{DISCUSSION}

A number of essential genes have been identified in $L$. pneumophila, but a method for studying expression of these genes has not yet been developed, and is thus required. In this study, we established the application of unstable Gfp as a vital marker to monitor L. pneumophila gene expression in macrophage-like cells.

Although the multifaceted potential of stable Gfp for analysis of fundamental biological phenomena has been described in detail for several organisms (Chalfie et al., 1994; Corish \& Tyler-Smith, 1999; Wang \& Hazelrigg, 1994), limited information is available on unstable Gfp usage in bacteria. The Gfp has some intrinsic advantages over other reporter systems: formation of the fluorescent chromophore is species independent, and does not require any additional cofactors. However, bacteria carrying gfpmut $3^{\star}$, which gives strong Gfp expression, do not multiply within J774.1 cells. Accumulation of Gfp in bacterial cells is thought to inhibit intracellular growth. We found that bacteria carrying $g f p$ mut $3^{*}$ showed an increase in intracellular proliferation of only 10 -fold during the first day, and they did not grow during the following days of incubation in J774.1 cells (Fig. 4). However, the unstable type of Gfp does not accumulate in cells, and represents only recent expression of $g f p$. Hence, we can suppose that this property of unstable Gfp permits L. pneumophila to multiply within host cells. The intracellular growth assay (Fig. 4) revealed that bacteria carrying the unstable type of Gfp multiplied to the same degree as wild-type $L$. pneumophila, and this was confirmed by electron microscopy (Fig. 5).

$g f p(\mathrm{AAV})$ was chosen from the four unstable $g f p$ genes available because the Gfp(AAV) protein was most susceptible to the action of indigenous housekeeping proteases, resulting in a protein variant with a half-life of $60 \mathrm{~min}$ when synthesized in L. pneumophila (Fig. 3). To study the kinetics of $L$. pneumophila gene expression within infected cells, transcriptional fusion vectors based on unstable Gfp were constructed, and a mutated $g f p(\mathrm{AAV})$ gene was used in the present experiment.

To examine the availability of the $g f p(\mathrm{AAV})$ gene as a reporter gene, icmS, icmT and icmQ genes were chosen because these genes are located most upstream of region II of the $i \mathrm{~cm} /$ dot gene clusters. It is known that the $\mathrm{IcmT}$ protein is essential for pore formation and intracellular trafficking of L. pneumophila within Acanthomoeba polyphaga (Molmeret et al., 2002). The IcmQ protein is also involved in the pore-forming process (Feldman et al., 2005). The IcmS protein has been identified as a chaperone of the IcmW protein, and has also been demonstrated to help export SidE. SidE is secreted very early during infection in macrophages. It plays an important role in the initial formation of the replicative phagosome, and is completely dependent on IcmS (Bardill et al., 2005). Pore formation is thought to take place when bacteria infect the host cells. As expected, we observed Gfp-mediated fluorescence from bacteria containing $\mathrm{P}_{i c m T^{-}}-g f p(\mathrm{AAV})$ and $\mathrm{P}_{i c m} \mathrm{Q}^{-} g f p(\mathrm{AAV})$ fusions during the early $(0-6 \mathrm{~h})$ stage of infection (Fig. 6). As for icmS, expression was strong during the early $(0-6 \mathrm{~h})$ and late $(20-23 \mathrm{~h})$ stages of infection. This finding was supported when fluorescent intracellular legionellae were observed by laser scanning confocal microscopy hourly for $24 \mathrm{~h}$ (Fig. 8 , and data not shown), and Gfp-expressing bacteria containing $\mathrm{P}_{\text {icms }}{ }^{-}$ $g f p(\mathrm{AAV}), \mathrm{P}_{i c m T^{-}} g f p(\mathrm{AAV})$ and $\mathrm{P}_{i c m \mathrm{Q}^{-}} g f p(\mathrm{AAV})$ fusions were not found during the interval from 6 to $20 \mathrm{~h}$ (date not shown).

Flow cytometric analysis revealed that unstable Gfp expression could be detected on or in infected cells (Fig. 6), and it showed that expression of the icm genes was high at $0 \mathrm{~h}$ of infection. It was thought that at this point in time, the fluorescent bacteria adhered to the host cells. At $3 \mathrm{~h}$ after infection, the expression levels of $i \mathrm{~cm} T$ and $i c m Q$ genes were very high. As both IcmT (Molmeret 
et al., 2002) and IcmQ (Feldman et al., 2005) proteins are involved in the pore-forming process, the results obtained from $3 \mathrm{~h}$ after infection could correlate with these investigations, and it appears that these proteins act in the same manner during infection of J774.1 cells. High expression of $i \mathrm{cmS}$ during the $6 \mathrm{~h}$ after infection can be explained by the role of the IcmS protein in the formation of replicative phagosomes within J774.1 cells. The icmS gene is more highly expressed than the $i \mathrm{~cm} T$ and $i \mathrm{~cm} Q$ genes during $23 \mathrm{~h}$ of infection (Fig. 6). It has been shown that IcmS-LvgA (Legionella virulence gene A) protein complex is important for Dot/Icm-dependent intracellular growth (Bardill et al., 2005; Ninio et al., 2005; Vincent \& Vogel, 2006). The fact that expression of the icmS gene increased during intensive multiplication of L. pneumophila in J774.1 cells suggests the importance of IcmS in $L$. pneumophila multiplication and survival in host cells.

RT-PCR was performed to determine the dynamics of bacterial gene expression during infection in J774.1 cells (Fig. 7). Compared with the results of the flow cytometric analysis (Fig. 6), gene expression in the early stage of infection was very low in the icm genes. This difference may be because intracellular bacteria were harvested from the host cells and used in RT-PCR assay, while both intracellular bacteria and bacteria adhering to cell surfaces were detected in the flow cytometric assay. Thereafter, only $i \mathrm{cmS}$ expression increased gradually. The fact that the promoter activity of $i \mathrm{cmS}, i \mathrm{~cm} T$ and $i \mathrm{~cm} Q$ genes was found to be different over the course of $23 \mathrm{~h}$ of infection may give a hint regarding their role in the intracellular process.

The reasons why we did not wash cells after in vitro phagocytosis in the flow cytometric assay are as follows. First, because bacterial transcription is a very rapid process, we had to save time between the point of infection to the point of observation. Second, chromophore formation of Gfp is dependent on temperature and oxygen. Third, the half-life of unstable Gfp is short, and it is degraded by indigenous housekeeping proteases. Finally, the washing procedure, including centrifugation and pipetting, may physically affect cells containing fluorescent bacteria. Furthermore, J774.1 cells are usually cultured in cell culture plates, and detached using trypsin. However, in order to prevent possible chemical influence by trypsin, ordinary Petri dishes were used during the flow cytometric experiment. As mentioned above, several procedures during the infection experiment were omitted in the flow cytometric experiment. Therefore, the result obtained in the flow cytometric analysis from 0 to $6 \mathrm{~h}$ is derived from intracellular fluorescent bacteria, and also from the fluorescent bacteria that adhered to the cells.

Bacteria expressing unstable Gfp within J774.1 cells were readily identified by laser scanning confocal microscope at different time points after infection. Phagocytosed $g f p$ expressing bacteria were observed hourly for up to $24 \mathrm{~h}$ after infection. A brighter green light was observed at $20 \mathrm{~h}$ after infection for the $i \mathrm{cmS}$ promoter, at $2 \mathrm{~h}$ after infection for the $i c m T$ promoter, and at $1 \mathrm{~h}$ after infection for the icm $Q$ promoter (Fig. 8). The signal of unstable Gfp was perhaps weaker than the signal of stable Gfp, but it was still visible.

Many investigations are being performed to elucidate the structure and function of known proteins, but there are not enough studies being carried out on the transcriptional programme of the human pathogen L. pneumophila during host infection. Identification of genes that are upregulated in vivo, and not in vitro, may explain their contribution to in vivo growth of $L$. pneumophila. Late in the life cycle, $L$. pneumophila upregulates genes that are predicted to promote transmission and manipulation of a new host, thereby priming it for the next attack. Substrates of the Dot/Icm secretion system, and other factors associated with invasion and virulence, and motility and type IV pilus machineries, and more than 90 proteins, have yet to be characterized. How L. pneumophila alternates between replicative and transmissive cell types, and which host factors are exploited during the replication phase, are only partly understood. Using unstable $g f p$ as a reporter gene, we were able to show that the $i \mathrm{cmS}, i \mathrm{~cm} T$ and $i \mathrm{~cm} Q$ genes were highly expressed at different time points in infection. This suggests the suitability of unstable Gfp for quantitative determination of promoter activities in L. pneumophila.

Our work should allow us to look at the function of other essential genes by constructing conditionally expressing strains. Here, we report, for what we believe is the first time, the expression of unstable Gfp in L. pneumophila. The advantage of this system is the ability of L. pneumophila, carrying an unstable type of Gfp, to multiply in host cells. This opens up the exciting possibility of being able to control L. pneumophila gene expression in vivo. The studies presented here using promoter-gfp fusion constructs demonstrate the utility of our Gfp reporter system in in vitro phagocytosis. The regulation of other genes of $L$. pneumophila may be performed using this functional method that is amenable to assay. Monitoring gene expression during the infection cycle will provide a valuable insight into how $L$. pneumophila responds to its environment, and makes the changes necessary for adaptation and infection. Moreover, this reporter system could play a central role in identifying and characterizing regulatory elements in L. pneumophila. Moreover, in contrast to stable reporters such as LacZ that can only monitor an increase in gene expression, the unstable Gfp variant can report both 'on' and 'off' states, and thus provide the basis for an even more accurate monitoring of gene expression (Southward \& Surette, 2002).

\section{ACKNOWLEDGEMENTS}

The authors thank H. Miyamoto for the kind gift of L. pneumophila strains, A. Takade and $\mathrm{H}$. Kajiwara for technical assistance, $\mathrm{H}$. Nakayama for critical advice on the manuscript, and Sharon Villanueva for carefully reading the manuscript. We also thank E. A. Baryshev for support during the experiments. This work was 
supported by grant 14370094 from the Ministry of Education, Science, Culture and Sports of Japan, and grant H14-047 from the Ministry of Health, Labour and Welfare of Japan.

\section{REFERENCES}

Abu Kwaik, Y., Gao, L. Y., Stone, B. J., Venkataraman, C. \& Harb, O. S. (1998). Invasion of protozoa by Legionella pneumophila and its role in bacterial ecology and pathogenesis. Appl Environ Microbiol 64, 31273133.

Andersen, J. B., Sternberg, C., Poulsen, L. K., Bjorn, S. P., Givskov, M. \& Molin, S. (1998). New unstable variants of green fluorescent protein for studies of transient gene expression in bacteria. Appl Environ Microbiol 64, 2240-2246.

Andrews, H. L., Vogel, J. P. \& Isberg, R. R. (1998). Identification of linked Legionella pneumophila genes essential for intracellular growth and evasion of the endocytic pathway. Infect Immun 66, 950-958.

Bardill, J. P., Miller, J. L. \& Vogel, J. P. (2005). IcmS-dependent translocation of SdeA into macrophages by the Legionella pneumophila type IV secretion system. Mol Microbiol 56, 90-103.

Blokpoel, M. C., O'Toole, R., Smeulders, M. J. \& Williams, H. D. (2003). Development and application of unstable GFP variants to kinetic studies of mycobacterial gene expression. J Microbiol Methods 54, 203-211.

Chalfie, M., Tu, Y., Euskirchen, G., Ward, W. W. \& Prasher, D. C. (1994). Green fluorescent protein as a marker for gene expression. Science 263, 802-805.

Chien, M., Morozova, I., Shi, S., Sheng, H., Chen, J., Gomez, S. M., Asamani, G., Hill, K., Nuara, J. \& other authors (2004). The genomic sequence of the accidental pathogen Legionella pneumophila. Science 305, 1966-1968.

Corish, P. \& Tyler-Smith, C. (1999). Attenuation of green fluorescent protein half-life in mammalian cells. Protein Eng 12, 1035-1040.

Cormack, B. P., Valdivia, R. H. \& Falkow, S. (1996). FACS-optimized mutants of the green fluorescent protein (GFP). Gene 173, 33-38.

Dumenil, G., Montminy, T. P., Tang, M. \& Isberg, R. R. (2004). IcmRregulated membrane insertion and efflux by the Legionella pneumophila IcmQ protein. J Biol Chem 279, 4686-4695.

Feldman, M., Zusman, T., Hagag, S. \& Segal, G. (2005). Coevolution between nonhomologous but functionally similar proteins and their conserved partners in the Legionella pathogenesis system. Proc Natl Acad Sci U S A 102, 12206-12211.

Horwitz, M. A. (1987). Characterization of avirulent mutant Legionella pneumophila that survive but do not multiply within human monocytes. J Exp Med 166, 1310-1328.

Horwitz, M. A. \& Silverstein, S. C. (1983). Intracellular multiplication of Legionnaires' disease bacteria (Legionella pneumophila) in human monocytes is reversibly inhibited by erythromycin and rifampin. J Clin Invest 71, 15-26.

Keiler, K. C. \& Sauer, R. T. (1996). Sequence determinants of Cterminal substrate recognition by the Tsp protease. J Biol Chem 271, 2589-2593.
Marra, A. \& Shuman, H. A. (1989). Isolation of a Legionella pneumophila restriction mutant with increased ability to act as a recipient in heterospecific matings. J Bacteriol 171, 2238-2240.

Marra, A., Blander, S. J., Horwitz, M. A. \& Shuman, H. A. (1992). Identification of a Legionella pneumophila locus required for intracellular multiplication in human macrophages. Proc Natl Acad Sci U S A 89, 9607-9611.

Molmeret, M., Alli, O. A., Radulic, M., Susa, M., Doric, M. \& Kwaik, Y. A. (2002). The C-terminus of IcmT is essential for pore formation and for intracellular trafficking of Legionella pneumophila within Acanthamoeba polyphaga. Mol Microbiol 43, 1139-1150.

Muto, A., Ushida, C. \& Himeno, H. (1998). A bacterial RNA that functions as both a tRNA and an mRNA. Trends Biochem Sci 23, 25-29.

Nagai, H., Kagan, J. C., Zhu, X., Kahn, R. A. \& Roy, C. R. (2002). A bacterial guanine nucleotide exchange factor activates ARF on Legionella phagosomes. Science 295, 679-682.

Ninio, S., Zuckman-Cholon, D. M., Cambronne, E. D. \& Roy, C. R. (2005). The Legionella IcmS-IcmW protein complex is important for Dot/Icm-mediated protein translocation. Mol Microbiol 55, 912-926.

Segal, G. \& Shuman, H. A. (1997). Characterization of a new region required for macrophage killing by Legionella pneumophila. Infect Immun 65, 5057-5066.

Segal, G. \& Shuman, H. A. (1998). How is the intracellular fate of the Legionella pneumophila phagosome determined? Trends Microbiol 6, 253-255.

Segal, G. \& Shuman, H. A. (1999). Legionella pneumophila utilizes the same genes to multiply within Acanthamoeba castellanii and human macrophages. Infect Immun 67, 2117-2124.

Sexton, J. A., Miller, J. L., Yoneda, A., Kehl-Fie, T. E. \& Vogel, J. P. (2004). Legionella pneumophila DotU and $\mathrm{IcmF}$ are required for stability of the Dot/Icm complex. Infect Immun 72, 5983-5992.

Southward, C. M. \& Surette, M. G. (2002). The dynamic microbe: green fluorescent protein brings bacteria to light. Mol Microbiol 45, 1191-1196.

Vincent, C. D. \& Vogel, J. P. (2006). The Legionella pneumophila IcmSLvgA protein complex is important for Dot/Icm-dependent intracellular growth. Mol Microbiol 61, 596-613.

Vogel, J. P., Andrews, H. L., Wong, S. K. \& Isberg, R. R. (1998). Conjugative transfer by the virulence system of Legionella pneumophila. Science 279, 873-876.

Wai, S. N., Mizunoe, Y., Takade, A., Kawabata, S. I. \& Yoshida, S. I. (1998). Vibrio cholerae O1 strain TSI-4 produces the exopolysaccharide materials that determine colony morphology, stress resistance, and biofilm formation. Appl Environ Microbiol 64, 3648-3655.

Wang, S. \& Hazelrigg, T. (1994). Implications for $b c d$ mRNA localization from spatial distribution of exu protein in Drosophila oogenesis. Nature 369, 400-403.

Zamboni, D. S., McGrath, S., Rabinovitch, M. \& Roy, C. R. (2003). Coxiella burnetii express type IV secretion system proteins that function similarly to components of the Legionella pneumophila Dot/ Icm system. Mol Microbiol 49, 965-976.

Edited by: T. P. Hatch 